(C) Elsevier Sequoia S.A., Lausanne - Printed in the Netherlands

\title{
WEAR OF DIMETHACRYLATE RESINS USED IN DENTAL COMPOSITES*
}

\section{J. M. POWERS, W. H. DOUGLAS and R. G. CRAIG}

School of Dentistry, The University of Michigan, Ann Arbor, Mich. 48109 (U.S.A.)

(Received September 8, 1978)

\section{Summary}

Wear of dimethacrylate resins used as the matrix phase in dental restorative composites was characterized by two-body abrasion and singlepass sliding. Ranking of the resins was obtained by both tests. Two resins that had low values of tangential force and track width also showed relatively ductile modes of surface failure for the normal loads tested. A monomethacrylate fluorine-containing resin did not show improved wear properties by these methods of testing.

\section{Introduction}

Dental composite restorative materials are typically. composed of a highly cross linked dimethacrylate resin reinforced with silanated inorganic filler particles (about $50 \mathrm{vol} . \%$ ). Clinical observation of composite restorations in posterior teeth has suggested that the inorganic filler particles become sufficiently exposed so as to exfoliate as the resin matrix wears away [1]. Improvements in the durability of composite resins may result from an understanding of the wear behavior of the resin matrix.

The purpose of this study was to characterize the wear of dimethacrylate resins used as the matrix phase in dental restorative composites by two-body abrasion and single-pass sliding.

\section{Materials and methods}

Five experimental resins were studied: A, TEGDMA; B, BisEDMA; C, BisGMA + EGDMA (1:1 by weight); D, BisEDMA + OFPMA (9:3 by weight); E, BisEDMA + OFPMA ( $3: 9$ by weight). The monomers used to

\footnotetext{
*This investigation was presented in part at the International Conference on Wear of Materials, Dearborn, Michigan, April $16-18,1979$.
} 
TABLE 1

Batch number and manufacturer of monomers studied

\begin{tabular}{|c|c|c|c|}
\hline Monomer & & Batch number & Manufacturer \\
\hline TEGDMA: & $\begin{array}{l}\text { Tetraethylene glycol dimethacrylate } \\
\text { (no. 2654) }\end{array}$ & $2 L-5-1-125$ & $\begin{array}{l}\text { Polysciences Inc., } \\
\text { Warrington, } \mathrm{Pa} \text {. } \\
18976\end{array}$ \\
\hline BisEDMA: & $\begin{array}{l}\text { Bisphenol A-bis ethyl methacrylate } \\
\text { (Diacryl 101) }\end{array}$ & - & $\begin{array}{l}\text { Akzo Chemie } \\
\text { Nederland bv, } \\
\text { Amsterdam, } \\
\text { Holland }\end{array}$ \\
\hline OFPMA: & $\begin{array}{l}\text { Octafluoro-1-pentylmethacrylate } \\
\text { (no. 0938) }\end{array}$ & $8-138$ & Polysciences Inc. \\
\hline BisGMA: & $\begin{array}{l}\text { Bisphenol A-bis (2-hydroxy-propyl) } \\
\text { methacrylate (no. } 3344 \text { ) }\end{array}$ & $2 L-25-6$ & Polysciences Inc. \\
\hline EGDMA: & $\begin{array}{l}\text { Ethylene glycol dimethacrylate } \\
\text { (no. 2214) }\end{array}$ & 1657 & Polysciences Inc. \\
\hline
\end{tabular}

formulate these resins are described in Table 1. The structural formulas of the monomers are shown in Fig. 1. Polymerization of the monomers was initiated by light from a $100 \mathrm{~W} 12 \mathrm{~V}$ tungsten projection bulb (PN 161 Riluma, Quarry Inc., Ann Arbor, Mich. 48104). The initiators were camphoroquinone (12489-3, Aldrich Chemical Co. Ltd., Gillingham, Dorset, Gt. Britain) and N,N-dimethyl aminoethyl methacrylate (71919, KochLight Laboratories Ltd., Colnbrook, Bucks, Gt. Britain) in concentrations of 0.75 and $0.50 \mathrm{wt} \%$ respectively. The resins were polymerized in molds for $30 \mathrm{~min}$ and then stored in water at $37^{\circ} \mathrm{C}$ for $24 \mathrm{~h}$ before testing.

Two-body abrasion was determined as described by Powers et al. [2] . Cylindrical specimens $(6 \mathrm{~mm}$ in diameter and $12 \mathrm{~mm}$ in length) of each resin were made in split stainless steel dies. Each specimen was held stationary in a jig under a normal load of $5.0 \mathrm{~N}$ (a stress of $0.18 \mathrm{MN} \mathrm{m}^{-2}$ ). Abrasion was caused by a commercial 600-grit $\mathrm{SiC}\left(\mathrm{KHN}, 2480 \mathrm{~kg} \mathrm{~mm}^{-2}\right.$ ) paper (Buehler Ltd., Evanston, Ill. 60204) and by experimental alumina (KHN, $2080 \mathrm{~kg}$ $\mathrm{mm}^{-2}$ ) and quartz (KHN, $820 \mathrm{~kg} \mathrm{~mm}^{-2}$ ) papers (RDC Industries, Philadelphia, Pa. 19132). The experimental papers have been described in detail by Rootare et al. [3]. The abrasive papers were attached to the table of a surface grinder (Grand Rapids 250, Gallmeyer and Livingston Co., Grand Rapids, Mich. 49502). The table moved at a speed of $0.25 \mathrm{~cm} \mathrm{~s}^{-1}$. Each specimen was abraded for a distance of $10 \mathrm{~m}$ with each pass of $25 \mathrm{~cm}$ made on a fresh abrasive surface. The rubbing surfaces were continually flushed with distilled water to remove wear debris. Six specimens of each resin were tested on each of the different abrasive papers. Wear was determined by measurement of the change in length of the specimen with use of a micrometer accurate to $0.001 \mathrm{~mm}$. The data are reported as volume loss per unit of travel $\left(\mathrm{mm}^{3} \mathrm{~mm}^{-1}\right)$. 

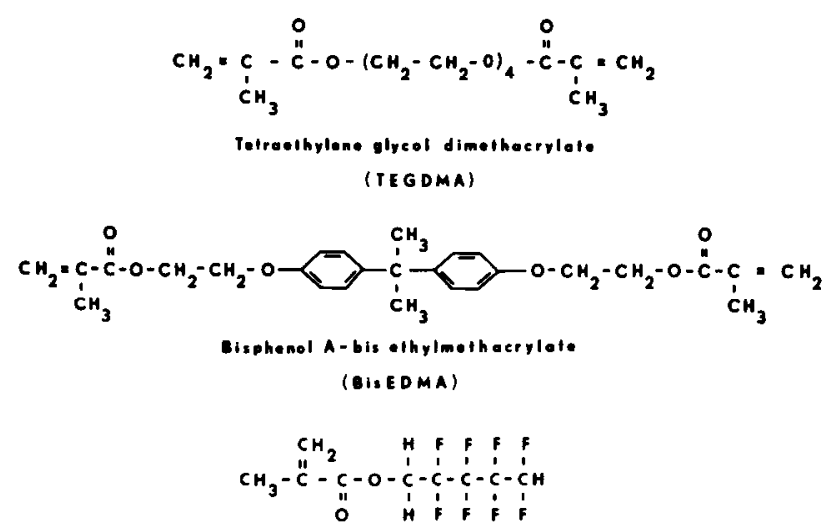

Octofluoro-l-peniylmethocrylote (OFPMA)

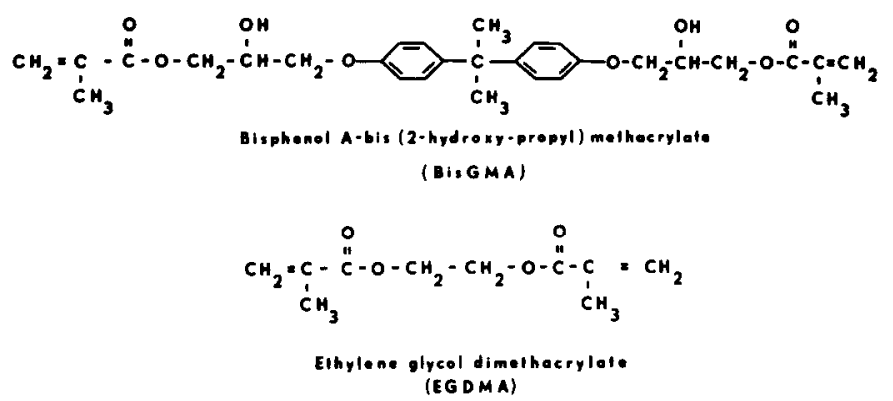

Fig. 1. Structural formulae of monomers used to formulate resins.

Wear caused by single-pass sliding was determined as described by Powers et al. [4]. The resins were polymerized in a cylindrical hole made in an acrylic rod. A glass slide was placed on the surface of the mold to provide a smooth surface on the resin sample. A diamond stylus $(360 \mu \mathrm{m}$ in diameter) was slid across the surface of the specimens at normal loads of $1.0-10 \mathrm{~N}$ in increments of $1.0 \mathrm{~N}$. The diamond slider was attached to a loading jig by a strain gauge transducer that allowed the tangential force to be recorded. The mold containing the sample was mounted on the table of a surface grinder moving at a speed of $0.025 \mathrm{~cm} \mathrm{~s}^{-1}$. Five specimens of each resin were tested. Tangential force and track width data were collected for each run. Track width was measured on a metallograph using a calibrated eyepiece. A scanning electron microscope was used to study the wear scars further.

\section{Results}

Mean values and standard deviations of two-body abrasion data are listed in Table 2 for the resins tested on silicon carbide, alumina and quartz abrasive papers. The means were compared by Tukey's intervals [5] 
TABLE 2

Two-body abrasion of resins by $\mathrm{SiC}$, alumina and quartz abrasive papers

\begin{tabular}{lllll}
\hline Code & Resin & \multicolumn{3}{l}{ Wear rate $\left(10^{-4} \mathrm{~mm}^{3} \mathrm{~mm}^{-1} \text { of travel }\right)^{*}$} \\
\cline { 3 - 5 } & & $\mathrm{SiC}$ & Alumina & Quartz \\
\hline A & TEGDMA & $22.0(1.7)$ & $4.00(0.48)$ & $2.62(0.24)$ \\
B & BisEDMA & $17.7(2.4)$ & $2.76(0.60)$ & $1.81(0.34)$ \\
C & BisGMA + EGDMA (1:1) & $15.5(0.7)$ & $3.52(0.59)$ & $1.97(0.33)$ \\
D & BisEDMA + OFPMA (9:3) & $19.1(1.0)$ & $3.01(0.54)$ & $2.33(0.22)$ \\
E & BisEDMA + OFPMA (3:9) & $32.2(2.8)$ & $5.43(0.71)$ & $3.64(0.26)$ \\
\hline
\end{tabular}

* Mean of six replications with standard deviation in parentheses.

computed from an analysis of variance [6] at the $95 \%$ level of confidence. For resins tested on SiC paper, Tukey's interval was $2.8 \mathrm{~mm}^{3} \mathrm{~mm}^{-1}$. For resins tested on alumina and quartz papers, Tukey's interval was $0.51 \mathrm{~mm}^{3}$ $\mathrm{mm}^{-1}$ for comparisons among resins and $0.23 \mathrm{~mm}^{3} \mathrm{~mm}^{-1}$ for comparisons between the abrasives. The resins are ranked statistically from highest to lowest wear rate for each abrasive in Table 3 .

\section{TABLE 3}

Statistical ranking of resins from highest to lowest wear rate for each abrasive

\begin{tabular}{|c|c|c|c|c|c|}
\hline \multirow{3}{*}{$\begin{array}{l}\text { Abrasive } \\
\mathrm{SiC}\end{array}$} & \multicolumn{5}{|c|}{ Wear rate* } \\
\hline & \multicolumn{3}{|c|}{ Highest } & \multicolumn{2}{|c|}{ Lowest } \\
\hline & E & A & $\mathrm{D}$ & B & $\mathrm{C}$ \\
\hline Alumina & $\mathrm{E}$ & A & $\mathrm{C}$ & $\mathrm{D}$ & B \\
\hline Quartz & $\mathrm{E}$ & $\mathbf{A}$ & $\mathrm{D}$ & $\mathrm{C}$ & B \\
\hline
\end{tabular}

*The underline means that there is no statistical difference between resins at the $95 \%$ level of confidence.

Mean values of tangential force and track width determined from singlepass sliding are plotted as a function of normal load in Figs. 2 and 3, respectively. Values of track width for resin A could not be measured. Typical values of the coefficient of variation for the tangential force and track width data were $7 \%$ and $3 \%$ respectively.

Three characteristic modes of surface failure were observed among the resins tested. Scanning electron photomicrographs of wear scars of resin $\mathrm{E}$ illustrating the ductile, brittle and catastrophic modes of failure are shown in 


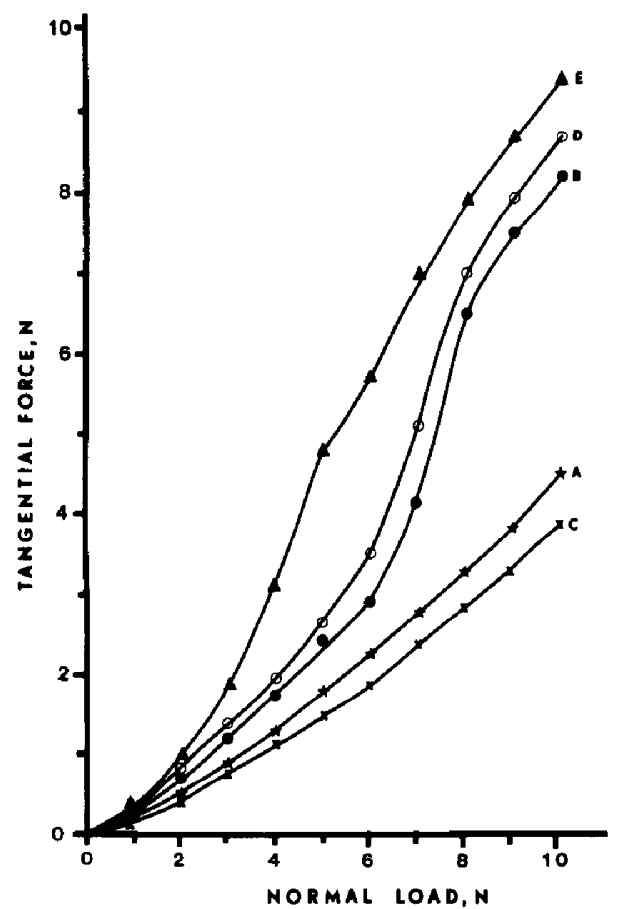

Fig. 2. Curves of tangential force us. normal load for the resins tested.

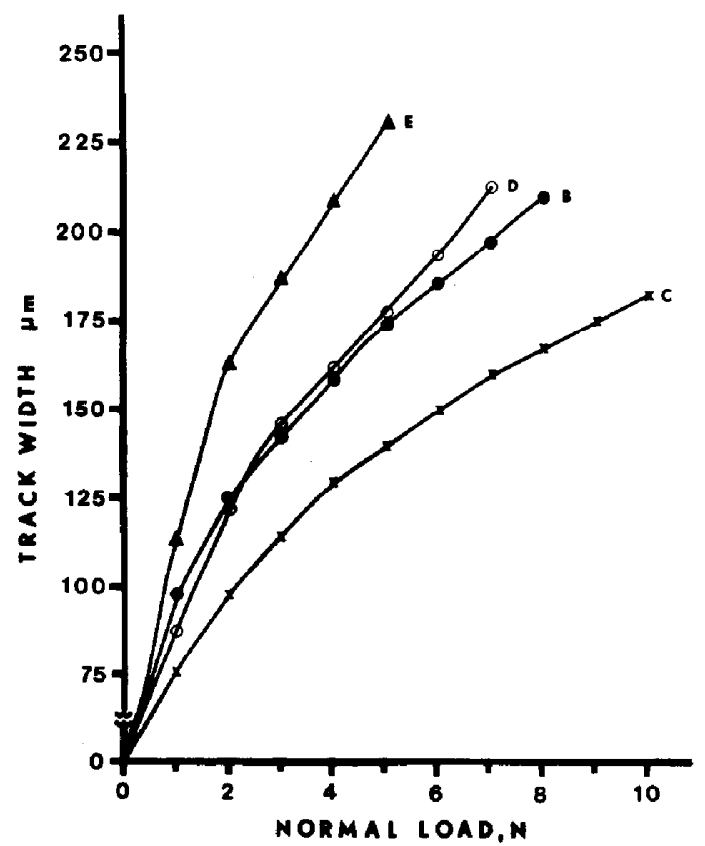

Fig. 3. Curves of track width us. normal load for the resins tested. 

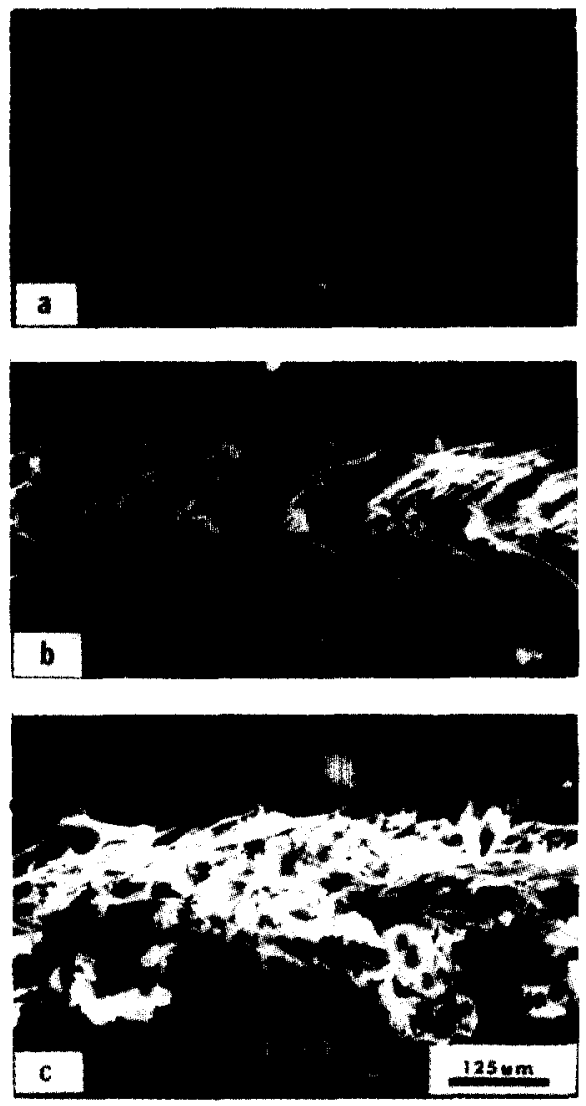

Fig. 4. Scanning electron photomicrographs showing modes of surface failure observed for resin E: (a) ductile; (b) brittle; (c) catastrophic. The normal loads, direction of motion of the diamond slider and the magnification are indicated. The tilt of the specimen was $45^{\circ}$.

TABLE 4

Ranges of normal load over which different modes of surface failure were observed

\begin{tabular}{llll}
\hline Code & \multicolumn{2}{l}{ Range of normal loads (N) } \\
\cline { 2 - 4 } & Ductile mode & \multicolumn{1}{l}{ Brittle mode } & Catastrophic mode \\
\hline A & $1.0-6.0$ & $7.0-10.0$ & - \\
B & $1.0-4.0$ & $5.0-6.0$ & $7.0-10.0$ \\
C & $1.0-10.0$ & - & - \\
D & $1.0-3.0$ & $4.0-7.0$ & $8.0-10.0$ \\
E & $1.0-2.0$ & 3.0 & $4.0-10.0$ \\
\hline
\end{tabular}

Fig. 4. The ranges of normal loads over which these modes of surface failure were observed are listed in Table 4. 


\section{Discussion}

The wear rate of the dimethacrylate resins during two-body abrasion was a function of the abrasive used. SiC caused the highest wear rate and quartz the lowest for each resin. Of the three abrasives tested, SiC was best able to discriminate among the resins. Even so, the differences in wear rate among B, C and D were not dramatic. The wear rates of A, B, C and D on $\mathrm{SiC}$ paper are comparable with or lower than values determined previously for commercial resins accelerated by amines or UV light to be between $1.70 \times 10^{-4}$ and $23.9 \times 10^{-4} \mathrm{~mm}^{3} \mathrm{~mm}^{-1}$ of travel $[2,7]$.

The single-pass sliding technique ranked the dimethacrylate resins in three groups. Resins $\mathrm{A}$ and $\mathrm{C}$ had the lowest values of tangential force, resins $B$ and $D$ had intermediate values and resin $E$ had the highest values. The slopes of the curves of tangential force versus normal load between 3.0 and $5.0 \mathrm{~N}$ were 0.45 and 0.35 for $\mathrm{A}$ and $\mathrm{C}, 0.61$ for both $\mathrm{B}$ and $\mathrm{D}$, and 1.48 for E.

The track width data were also ranked in three groups. Resin $\mathrm{C}$ had the lowest values of track width as a function of normal load, resins $B$ and $D$ had intermediate values and resin $E$ had the highest values. Values of the track width for A could not be measured. The data of track width and tangential force appear to be directly related suggesting that penetration of the diamond slider into the resin is responsible for the tangential force. At higher normal loads for resins B, D and E, however, the catastrophic mode of failure (see Table 4) caused the tangential force to be less than what would have been expected from penetration alone.

The relatively ductile mode of surface failure of resins $A$ and $C$ over the normal loads tested suggest that these crosslinked structures are better able to accommodate strain than the structures of B, D or E, all of which failed catastrophically at the higher normal loads. Further research should pursue the relative effect of the addition of inorganic filler to $\mathrm{A}$ and $\mathrm{C}$ to determine if the resin matrix remains ductile in behavior.

The 3:9 BisEDMA-OFPMA resin performed relatively poorly in both the two-body abrasion and single-pass sliding tests; however, the desirability of fluorine-containing resins appears to be in their resistance to long term chemical degradation because of their hydrophobic nature $[8,9]$. It should be noted that the OFPMA is a monomethacrylate. Further research should pursue the development of fluorine-containing dimethacrylate resins that can be copolymerized with other suitable dimethacrylate resins, since good wear resistance appears to require a tough crosslinked matrix as well as chemical stability.

\section{Conclusions}

Wear of dimethacrylate resins was characterized by two-body abrasion and single-pass sliding. Wear rates determined by abrasion with SiC paper 
were comparable with or lower than values obtained on commercially formulated unfilled dimethacrylate resins. A BisGMA-FGDMA copolymer and a TEGDMA resin had the lowest values of tangential force and track width as determined by single-pass sliding. Both of these resins showed relatively ductile modes of surface failure over the range of normal loads tested. The addition of a fluorine-containing methacrylate to BisEDMA did not improve the wear resistance of the copolymer as tested.

\section{Acknowledgments}

This investigation was supported in whole by USPHS Research Grant DE-03416 from the National Institute of Dental Research, National Institutes of Health, Bethesda, Md. 20014.

\section{References}

1 R. P. Kusy and K. F. Leinfelder, Pattern of wear in posterior composite restorations, J. Dent, Res., 56 (1977) 544.

2 J. M. Powers, L. J. Allen and R. G. Craig, Two-body abrasion of commercial and experimental restorative and coating resins and an amalgam, Am. Dent. Ass. J., 89 (1974) $1118 \cdot 22$.

3 H. M. Rootare, J. M. Powers and R. G. Craig, Wear of composites by abrasives of varying hardness, J. Dent. Res., in the press.

4 J. M. Powers, J. C. Roberts and R. G. Craig, Surface failure of commercial and experimental restorative resins, J. Dent. Res., 55 (1976) $432-36$.

5 W. C. Guenther (ed.), Analysis of Variance, Prentice-Hall, Englewood Cliffs, N.J., 1964.

6 J. Dalby, BMD8V-Analysis of variance, Statistical Research Laboratory, University of Michigan, Ann Arbor, 1968.

7 J. C. Roberts, J. M. Powers and R. G. Craig, Wear of commercial pit and fissure sealants, J. Dent. Res., 56 (1977) 692.

8 R, G. Craig and T. K. Wang, An experimental hydrophobic composite restorative system, Abstr. J. Dent. Res., 56 (Spec. Issue B) (1977) B216.

9 W. H. Douglas, R. G. Craig and C.-J. Chen, Visible light initiated hydrophobic composite from fluoromethacrylate, Abstr. J. Dent. Res., 57 (Spec. Issue A) (1978) 250. 